\title{
Temporal and life history related trends of perfluorochemicals in harbor porpoises from the Danish North Sea
}

\author{
Anders Galatius ${ }^{a}$, Rune Dietz ${ }^{\mathrm{a}, *}$, Frank F. Rigét ${ }^{\mathrm{a}}$, Christian Sonne ${ }^{\mathrm{a}}$, Carl Christian Kinze ${ }^{\mathrm{b}}$, Christina Lockyer $^{\mathrm{c}}$, \\ Rossana Bossi ${ }^{\mathrm{d}}$

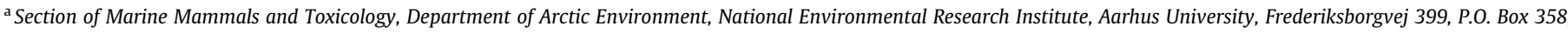 \\ DK-4000 Roskilde, Denmark \\ ${ }^{\mathrm{b}}$ Rosenørns Allé 55 2. tv., 1970 Frederiksberg C, Denmark \\ ${ }^{\mathrm{c}}$ The North Atlantic Marine Mammal Commission, Tromsø Science Park, P.O. Box 6453, N-9294 Tromsø, Norway \\ ${ }^{\mathrm{d}}$ Department of Atmospheric Environment, National Environmental Research Institute, Aarhus University, Frederiksborgvej 399, P.O. Box 358, DK-4000 Roskilde, Denmark
}

\section{A R T I C L E I N F O}

\section{Keywords:}

Harbor porpoise

Life history

Liver

North Sea

Perfluorinated chemicals

Temporal trend

\begin{abstract}
A B S T R A C T
Eighty-five stranded or bycaught harbor porpoises collected from the Danish North Sea between 1980 and 2005 were analyzed for perfluorochemicals in the liver. PFOS was the predominant compound, making up on average $88.9 \%$ of the $\sum$ PFC, followed by PFOSA (7.8\%). PFUnA (1.9\%) and PFDA (1.2\%) were detected in most samples. PFHxS, PFNA and PFOA were only found in a minority of the samples. We found substantial differences in PFC concentrations among life history stages, the highest concentrations were found in neonates, suckling juveniles and lactating females. Such differences should be considered when PFC levels in wildlife are evaluated. The high concentrations found in young porpoises are of concern as PFCs have known toxic effects on the development of the central nervous system and reproductive organs. Despite efforts to reduce PFC emissions, a decreasing temporal trend of concentrations was not detected for any compound. PFCA concentrations were found to be increasing.
\end{abstract}

(c) 2011 Elsevier Ltd. All rights reserved.

\section{Introduction}

Perfluorochemicals (PFCs) are widely used synthetic compounds with various applications such as fire-fighting foams, cleaners, lubricants and various coatings (Kissa, 2001). They have been shown to bioaccumulate, be persistent in biota and widespread (Giesy and Kannan, 2001; Kissa, 2001; Kannan et al., 2001, 2005; Tomy et al., 2004). Two PFCs, perfluorooctane sulfonic acid (PFOS) and perfluorooctane sulfonyl fluoride (PFOS-F) have recently been included under the Stockholm Convention on persistent organic pollutants (POPs) (Wang et al., 2009). Emerging evidence suggests reproductive toxicity (Lau et al., 2003; Luebker et al., 2005), neurotoxicity (Johansson et al., 2008; Liu et al., 2010), hepatotoxicity (Miller et al., 1975; Malinverno et al., 2005) and potential effects on metabolism (Berthiaume and Wallace, 2002). Perfluorooctanoic acid (PFOA) is considered to be a likely human carcinogen (Upham et al., 2009). Unlike most other POPs which accumulate in lipid-rich tissue, PFCs bind to blood proteins and accumulate mainly in the liver, kidney and bile secretions (Jones et al., 2003). Due to the observed toxicity of PFOS, the 3M Company commenced reduction of PFOS production in 2001 (Butt et al., 2007).

\footnotetext{
* Corresponding author. Tel.: +45 46301938; fax: +45 46301914

E-mail address: rdi@dmu.dk (R. Dietz).
}

Given the persistence and bioaccumulation potential of PFCs, their toxicity to wildlife is of great concern. Marine mammals occupy the highest trophic levels in the marine food web and are thus exposed to very high concentrations of persistent compounds. The harbor porpoise (Phocoena phocoena) is the only cetacean species found consistently throughout the Danish waters. In porpoises from the Baltic and North Sea, PFOS is the dominant PFC (Van de Vijver et al., 2004). These authors found higher PFOS concentrations in the German Baltic and Denmark than in samples from Norway and Iceland. Combinations of PFOS levels and stable carbon isotopes indicate that porpoises feeding near-shore have higher loads than porpoises feeding further from shore (Van de Vijver et al., 2004). PFOS levels similar to those found by Van de Vijver et al. (2004) were observed in liver of harbor porpoises stranded or caught around UK coastal waters in 1992-2003 (Law et al., 2008), where mean concentration was $546 \pm 610 \mathrm{ng} \mathrm{g}^{-1}$.

While PFCs are increasing significantly with age in liver tissue of polar bears (Ursus maritimus) (Sonne et al., 2008) and do not show age trends in ringed seals (Pusa hispida) (Butt et al., 2008), the dynamics of these compounds may be different for small cetaceans such as harbor porpoises. For example, Van de Vijver et al. (2003) found significantly lower levels of PFOS in adult North Sea harbor porpoises than in juveniles. In a sample of porpoises from the Barents Sea, the highest concentration of PFOS in liver tissue was 
found in a fetus with $224 \mathrm{ng} \mathrm{g}^{-1}$, compared to $87 \mathrm{ng} \mathrm{g}^{-1}$ in the mother (Van de Vijver et al., 2004).

In the Arctic, far from local sources of PFCs, temporal trends have been studied in a number of species. The longest continuous time series has been presented for the East Greenland polar bears, where age-harmonized data on juvenile bears were presented from 19 sampling years within the period 1984-2006. Significant annual increases were found for 7 out of 8 PFCs analyzed (Dietz et al., 2008). Similar increases have been found in bears from Canada and Alaska in the period 1982-2002 (Smithwick et al., 2006). Studies of ringed seals from Greenland waters have, however, shown increases in PFCs in both East and West Greenland between 1982 and 2003 (Bossi et al., 2005). Time trend studies on PFCs in Canadian ringed seals from two regions have both shown increases in some cases followed by decreases, depending on the area, period and compound in question (Butt et al., 2007). Danish waters are situated between two potentially large outlets of pollutants; the Baltic to the east and the Elbe and Rhine to the west are carrying water from catchment areas including most of northern Europe. Thus, Danish samples can be useful for assessment of contributions of these sources. In the Baltic, an increasing trend in the PFOS concentration in guillemot (Uria aalge) eggs from 1968 to 2003 has been reported (Holmstrom et al., 2005). A similar trend was found in Baltic herring gull (Larus argentatus) eggs (Rüdel et al., 2010). In the latter study, eggs from the North Sea had higher loads than Baltic eggs in most years, but in the North Sea, a consistent time trend was not evident. In a recent study Ahrens et al. (2009) have examined temporal trends of PFCs in harbor seals (Phoca vitulina) from the German Bight in the period 1999-2008. PFOS was the dominant PFC found in the samples with a maximum concentration of $3676 \mathrm{ng} \mathrm{g}^{-1}$. A decline in PFOS concentrations was observed between 1999 and 2008, but the decreasing trend was not statistically significant.

In the present paper, we present PFC measurement in a temporal series of liver samples from harbor porpoises from Danish waters from 1980 to 2005. Beside this, we explore age, life history and sexrelated trends and discuss the biological meaning of these factors.

\section{Materials and methods}

\subsection{Samples and age determination}

Harbor porpoises were collected from the southern North Sea from 1980 to 2005 in cooperation with Natural History Museum, University of Copenhagen and DTU Aqua. Samples were frozen to $-20{ }^{\circ} \mathrm{C}$, shipped to Roskilde (DK) and stored at $-20^{\circ} \mathrm{C}$. In the laboratory, liver samples were lightly thawed before chemical analysis was performed. The ages of the porpoises were estimated by counting annual layering in decalcified thin sections $(25 \mu \mathrm{m})$ of teeth from the central lower jaw stained in hematoxylin, as described by Hohn and Lockyer (1995). Ages ranged from 0 to 21 years, however, only five specimens were older than eight years. Geographical distribution of the samples is illustrated in Fig. 1 and basic biological parameters of the sample are listed in Table 1. Data regarding reproductive status were recorded from the dissection journals and the specimens were divided among the following life history stages: neonates (NEO; $n=7$ ) were defined by an unhealed umbilical wound or very little dentine deposited inside the neonatal line. Sucklings (SU; $n=10$ ) were defined as animals without a completed annual layer collected in July-February. We expect parturition to occur in late June or early July (Sørensen and Kinze, 1994) and suckling to last for 8-10 months with gradual weaning (Lockyer, 2003). Immature animals (IM; $n=37$ ) were defined as non-suckling, sexually immature animals. Mature males (MA; $n=16$ ) were defined as sexually mature males.

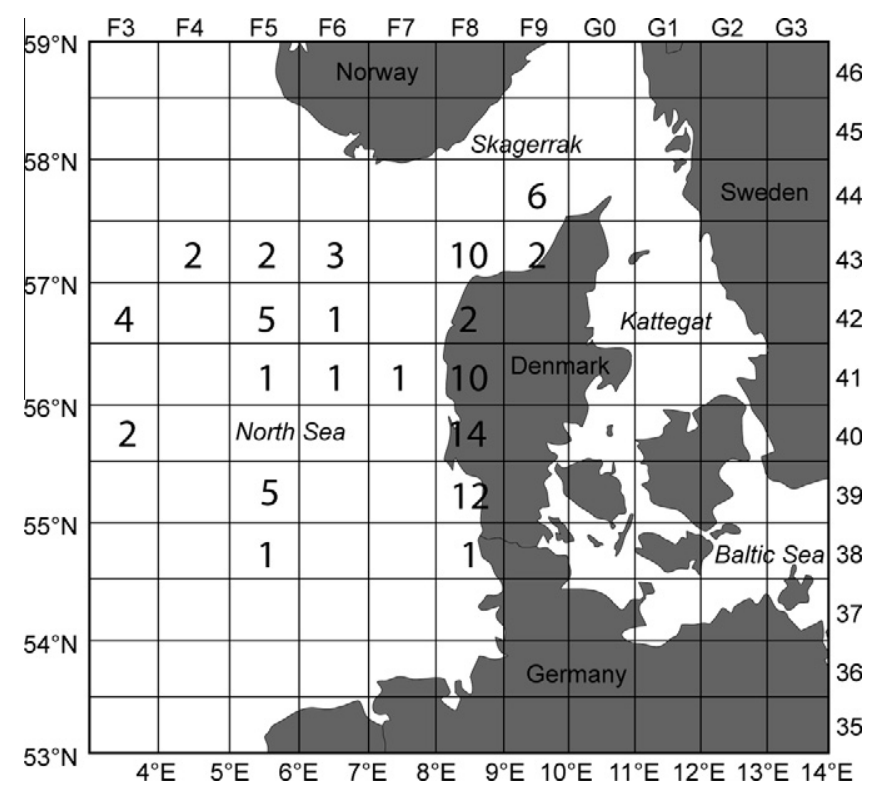

Fig. 1. Map of the Danish North Sea. Grid square coordinates defined by the International Council for Exploration of the Sea (ICES) are given on top and right, latitude and longitude left and bottom. The numbers of specimens from each grid square are given.

Mature females were initially divided among four categories, pregnant (PR; $n=4)$, lactating ( $n=1)$, pregnant and lactating $(n=3)$ and resting (RE; $n=1$, females that were neither pregnant nor lactating). The one lactating and the three pregnant and lactating females had similar PFC profiles that were very different from other mature animals, so it was decided to pool these four animals in one category; lactating (LA). For four sexually mature females, there was no available information on reproductive status. These specimens were excluded from the statistical analyses. Furthermore, sexual maturity was not known for one female and one male. The female was excluded from statistical analyses while the male was included in time-trend analyses as it was known not to be in the life history categories excluded here, namely NEO, SU and LA.

\subsection{Extraction and analysis}

Liver samples were analyzed for concentrations of perfluorohexanesulfonate (PFHxS), PFOS, perfluorooctanesulfonamide (PFOSA), PFOA, perfluorononanoic acid (PFNA), perfluorodecanoic acid (PFDA) and perfluoroundecanoic acid (PFUnA). The extraction method was based on ion pairing as described by Bossi et al. (2005). ${ }^{13} \mathrm{C}_{2}$-PFDA and ${ }^{13} \mathrm{C}_{4}$-PFOS were used as surrogate standards. All standards were provided by Wellington Laboratories (Guelph, ON, Canada). Instrumental analysis was performed by liquid chromatography-tandem mass spectrometry (LC-MS-MS) with electrospray ionization (ESI). The extracts $(20 \mu \mathrm{L}$ injection volume) were chromatographed on a C18 Betasil column (2.1 $50 \mathrm{~mm}$, Thermo Hypesil-Keystone, Bellafonte, PA) using an Agilent 1100 Series HPLC (Agilent Technologies, Palo Alto, CA). The HPLC was interfaced to a triple quadrupole API 2000 (Sciex, Concorde, Ontario, Canada) equipped with a Turbo Ion Spray source operating in negative ion mode. Instrument set-up, quality assurance and calibration procedures as well as the standards and reagents used are described in detail by Bossi et al. (2005).

\subsection{Quality assurance}

The samples were extracted and analyzed in batches together with a procedural blank. The target compounds were not detected 
Table 1

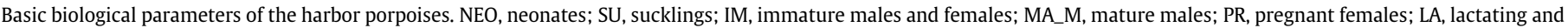
lactating + pregnant females; RE, resting females (not lactating and not pregnant).

\begin{tabular}{|c|c|c|c|c|c|c|c|c|c|c|c|c|c|c|c|c|}
\hline Year & $N$ & $\begin{array}{l}\text { Mean } \\
\text { age }\end{array}$ & $\begin{array}{l}\text { Min } \\
\text { age }\end{array}$ & $\begin{array}{l}\text { Max } \\
\text { age }\end{array}$ & $\begin{array}{l}\text { Mean } \\
\mathrm{TL}\end{array}$ & $\begin{array}{l}\text { Min } \\
\text { TL }\end{array}$ & $\begin{array}{l}\text { Max } \\
\text { TL }\end{array}$ & $N$ Males & $N$ Females & $N$ NEO & $N \mathrm{SU}$ & $N$ IM & NMA_M & $N$ PR & $N$ LA & $N$ RE \\
\hline 1980 & 14 & 2.4 & 0 & 8 & 127.3 & 93 & 146 & 8 & 6 & 0 & 3 & 6 & 3 & 0 & 2 & 0 \\
\hline 1989 & 4 & 3.5 & 1 & 5 & 129.8 & 121 & 140 & 2 & 2 & 0 & 0 & 2 & 1 & 0 & 1 & 0 \\
\hline 1990 & 2 & 6.0 & 0 & 12 & 118.5 & 67 & 170 & 0 & 2 & 1 & 0 & 0 & 0 & 0 & 0 & 1 \\
\hline 1991 & 2 & 0.5 & 1 & 1 & 108.8 & 97 & 121 & 2 & 0 & 0 & 1 & 1 & 0 & 0 & 0 & 0 \\
\hline 1992 & 4 & 2.3 & 1 & 6 & 124.3 & 104 & 156 & 0 & 4 & 0 & 0 & 3 & 0 & 0 & 0 & 0 \\
\hline 1997 & 22 & 4.5 & 0 & 21 & 134.2 & 109 & 165 & 14 & 8 & 0 & 1 & 9 & 6 & 4 & 0 & 0 \\
\hline 1998 & 11 & 2.3 & 0 & 8 & 118.4 & 71 & 147 & 9 & 2 & 1 & 3 & 4 & 3 & 0 & 0 & 0 \\
\hline 1999 & 11 & 2.9 & 0 & 10 & 112.5 & 67 & 150 & 6 & 5 & 3 & 1 & 4 & 1 & 0 & 0 & 0 \\
\hline 2000 & 8 & 2.1 & 0 & 7 & 117.9 & 70 & 153 & 2 & 6 & 2 & 1 & 2 & 1 & 0 & 1 & 0 \\
\hline 2005 & 7 & 1.0 & 0 & 5 & 121.4 & 112 & 145 & 1 & 6 & 0 & 0 & 6 & 1 & 0 & 0 & 0 \\
\hline All & 85 & 3.0 & 0 & 21 & 124.1 & 67 & 170 & 44 & 41 & 7 & 10 & 37 & 16 & 4 & 4 & 1 \\
\hline
\end{tabular}

in any of the blank samples. The detection limit of the analytical method (MDL) was defined as those concentrations of the analytes needed to produce a signal-to-noise ratio $(S / N)$ of 3:1. Mean recoveries $(n=5)$ of the analytes were determined in spiked liver matrix (concentration: $50 \mathrm{ng} \mathrm{g}^{-1}$ wet weight). Detection limits and recoveries of the analyzed compounds are summarized in Table 2. Concentrations of the analytes in samples have not been corrected for recovery as calibration standards followed the same extraction procedure as samples. For each batch a sample was randomly selected and extracted in triplicate in order to evaluate the repeatability of the analytical method. The reproducibility of the method based on 8 repetitions of triplicates is summarized in Table 2. PFOA was not included in the statistical analysis, as it was only present in three samples.

\subsection{Statistical methods}

Non-parametric statistical tests such as Kruskal-Wallis rank sum test and Spearman rank correlation were preferred over parametric tests, in testing the influence of life history stages on PFC concentrations and correlations among compounds, in order to reduce the influence of extreme values and the relatively many values below detection limits of some compounds. Furthermore, the assumptions of parametric tests of normality and variance homogeneity could not be verified in all cases, even after logtransformations.

Analyses of temporal trends followed the ICES (International Council for the Exploitation of the Sea) temporal trend assessment procedure (Nicholson et al., 1998). The log-median concentration is used as annual PFA index value. The total variation over time is partitioned into a linear and a non-linear component. Linear regression analysis is applied to describe the linear component and a LOESS smoother (locally weighted scatter plot using a weighted quadratic least squares regression smoothing) with a window width of 7 years is applied to describe the non-linear component. The linear and non-linear components are tested by means of an analysis of variance. The theory behind the method is described in detail by Fryer and Nicholson (1999, 2002). The statistical analyses were performed using the statistical package $\mathrm{R}(\mathrm{R}$ Development Core Team, 2008).

Table 2

Detection limits (DL), average recoveries $(n=5)$ and reproducibility (\%) of the analyzed compounds.

\begin{tabular}{lccccccc}
\hline Compound & PFHxS & PFOS & PFOSA & PFOA & PFNA & PFDA & PFUnA \\
\hline DL (ng g $^{-1}$ ww) & 0.8 & 0.2 & 0.5 & 1.2 & 1.4 & 8.8 & 0.7 \\
Recovery (\%) & 80 & 92 & 98 & 110 & 111 & 90 & 93 \\
Reproducibility (\%) & 8 & 26 & 17 & n.c. & 17 & 33 & 32 \\
\hline
\end{tabular}

n.c., not calculated.

\section{Results and discussion}

All seven PFC compounds were detected in the harbor porpoise liver samples. PFOS was the dominant compound, making up on average $88.9 \%$ of the measured PFCs, followed by PFOSA (7.8\%). PFUnA (1.9\%) and PFDA (1.2\%) were also detected in most samples. PFOA was below detection limit in all but three of the samples, PFHxS in $39 \%$ of the samples and PFNA in $80 \%$ of the samples. A similar distribution of PFCs has been found in other marine mammals, e.g., Northwest Atlantic and North Sea harbor seals (Shaw et al., 2009; Ahrens et al., 2009), Nunavut polar bears (Martin et al., 2004), Greenland ringed seal (Bossi et al., 2005) and Florida bottlenose dolphins (Houde et al., 2006).

\subsection{Correlations among the analyzed PFCs}

Like Ahrens et al. (2009) who studied PFCs in harbor seals in the North Sea, we found highly significant correlations of the concentrations of the two perfluorinated carboxylic acids (PFCAs) consistently found (PFUnA and PFDA) and between these two and PFOS. This may indicate a common source of the PFCs (Smithwick et al., 2005). PFOSA concentrations, however, were not correlated to the other compounds, which may be caused by differences of metabolism or excretion patterns among life history stages (see below).

\subsection{Geographical trends of PFCs in harbor porpoises}

The concentrations of PFOS found in the Danish waters are similar in magnitude to what has earlier been reported from smaller samples of harbor porpoise from the North Sea and Denmark (Van de Vijver et al., 2003, 2004) and the UK (Law et al., 2008). However the Danish harbor porpoises had substantially greater concentrations than harbor porpoises from more northerly locations in Norway and Iceland (Van de Vijver et al., 2004).

\subsection{Trends related to age, sex and life history}

\subsubsection{PFOS}

There were seven neonate porpoises in our samples. Among these seven specimens, we found three of the four highest PFOS concentrations (median $868 \mathrm{ng} \mathrm{g}^{-1} \mathrm{ww}$; range: $258-2460$; Table 3 and Fig. 2) in our entire sample of 85 animals. As neonates can be assumed to have received no or very little milk, these data indicate substantial placental transfer of PFOS. Placental transfer of PFOA and PFOS has also been demonstrated in humans where PFOA was generally found in higher concentrations in umbilical cord plasma than in maternal plasma, PFOS in lower concentrations (Midasch et al., 2007). Another reason for high concentrations in neonates is probably the lack of urinary and fecal excretion during 
Table 3

List of PFC data from the analyzed years and the life history stages including mean, standard deviation (SD), median and range. $<$ DL, below detection limit.

\begin{tabular}{|c|c|c|c|c|c|c|c|c|c|c|c|c|c|c|c|c|c|c|c|c|c|}
\hline \multirow[t]{2}{*}{ Year } & \multirow[t]{2}{*}{$N$} & \multicolumn{5}{|l|}{ PFOS } & \multicolumn{5}{|c|}{ PFOSA } & \multicolumn{5}{|l|}{ PFDA } & \multicolumn{5}{|l|}{ PFUnA } \\
\hline & & Mean & SD & Med & Min & Max & Mean & SD & Med & Min & Max & Mean & SD & Med & Min & Max & Mean & SD & Med & Min & Max \\
\hline & & \multicolumn{20}{|c|}{ Annual data } \\
\hline 1980 & 9 & 251.0 & 88.1 & 245.8 & 101.7 & 366.3 & 10.1 & 5.7 & 10.7 & 3.7 & 21.5 & 0.9 & 0.5 & 0.8 & $<\mathrm{DL}$ & 1.8 & 1.7 & 1.9 & 1.3 & 0.4 & 6.6 \\
\hline 1989 & 3 & 486.0 & 143.4 & 467.0 & 353.0 & 638.0 & 40.9 & 20.9 & 44.6 & 18.4 & 59.6 & 9.2 & 9.2 & 8.3 & $<\mathrm{DL}$ & 18.8 & 6.3 & 2.2 & 5.9 & 4.3 & 8.7 \\
\hline 1990 & 1 & 523.0 & - & 523.0 & 523.0 & 523.0 & 46.8 & - & 46.8 & 46.8 & 46.8 & 11.4 & - & 11.4 & 11.4 & 11.4 & 5.5 & - & 5.5 & 5.5 & 5.5 \\
\hline 1991 & 1 & 190.0 & - & 190.0 & 190.0 & 190.0 & 35.2 & - & 35.2 & 35.2 & 35.2 & $<\mathrm{DL}$ & - & $<\mathrm{DL}$ & $<\mathrm{DL}$ & $<\mathrm{DL}$ & 2.9 & - & 2.9 & 2.9 & 2.9 \\
\hline 1992 & 4 & 944.5 & 629.6 & 933.0 & 212.0 & 1700.0 & 23.0 & 13.4 & 20.3 & 10.9 & 40.3 & 5.4 & 3.2 & 5.2 & 1.8 & 9.3 & 4.5 & 1.4 & 4.3 & 3.0 & 6.3 \\
\hline 1997 & 20 & 293.3 & 131.1 & 276.5 & 63.0 & 523.0 & 29.7 & 11.6 & 26.9 & 15.7 & 59.0 & 3.3 & 1.4 & 3.3 & $<\mathrm{DL}$ & 5.8 & 6.9 & 2.4 & 6.3 & 2.6 & 12.1 \\
\hline 1998 & 7 & 319.7 & 284.1 & 200.0 & 55.0 & 788.0 & 28.6 & 8.9 & 30.5 & 11.8 & 39.0 & 4.8 & 5.2 & 4.5 & $<\mathrm{DL}$ & 14.4 & 6.9 & 2.8 & 7.5 & 3.0 & 11.3 \\
\hline 1999 & 7 & 305.6 & 146.7 & 391.0 & 89.0 & 447.0 & 16.3 & 10.1 & 13.0 & 7.0 & 32.1 & 3.7 & 3.4 & 1.3 & $<\mathrm{DL}$ & 9.4 & 3.9 & 2.2 & 4.2 & 0.8 & 7.6 \\
\hline 2000 & 4 & 359.8 & 182.0 & 391.0 & 123.0 & 534.0 & 15.5 & 9.9 & 12.0 & 7.8 & 30.0 & 8.4 & 6.3 & 7.9 & 2.9 & 15.0 & 12.9 & 10.8 & 7.9 & 6.7 & 29.0 \\
\hline 2005 & 6 & 422.0 & 363.2 & 419.0 & 53.0 & 993.0 & 67.5 & 57.0 & 61.4 & 6.7 & 186.0 & 11.5 & 9.5 & 12.8 & $<\mathrm{DL}$ & 29.3 & 16.2 & 5.8 & 18.1 & 6.7 & 22.0 \\
\hline All & 62 & 362.6 & 279.6 & 300.0 & 53.0 & 1700.0 & 29.1 & 25.9 & 25.0 & 3.7 & 186.0 & 4.8 & 5.4 & 3.2 & $<\mathrm{DL}$ & 29.3 & 6.8 & 5.4 & 6.0 & 0.4 & 29.0 \\
\hline Stage & & \multicolumn{20}{|c|}{ Life history stage data } \\
\hline NEO & 7 & 1065.3 & 804.6 & 868.0 & 258.0 & 2460.0 & 3.8 & 3.0 & 2.4 & $<\mathrm{DL}$ & 8.6 & 17.9 & 14.5 & 18.4 & 5.1 & 46.4 & 7.9 & 6.5 & 6.8 & 2.2 & 21.3 \\
\hline SU & 10 & 802.1 & 792.4 & 642.0 & 91.0 & 2927.8 & 16.1 & 13.6 & 11.1 & 5.9 & 50.0 & 8.4 & 8.7 & 4.3 & $<\mathrm{DL}$ & 26.2 & 11.9 & 13.2 & 5.6 & 1.8 & 40.0 \\
\hline IM & 37 & 397.3 & 327.0 & 317.0 & 55.0 & 1700.0 & 29.3 & 31.4 & 20.3 & 5.3 & 186.0 & 5.3 & 6.1 & 3.2 & $<\mathrm{DL}$ & 29.3 & 7.5 & 6.5 & 6.3 & $<\mathrm{DL}$ & 29.0 \\
\hline MA_M & 16 & 278.1 & 172.8 & 261.2 & 53.0 & 788.0 & 29.6 & 17.7 & 28.9 & 3.7 & 59.3 & 3.7 & 4.0 & 3.0 & $<\mathrm{DL}$ & 14.4 & 6.2 & 3.4 & 6.5 & $<\mathrm{DL}$ & 12.1 \\
\hline PR & 4 & 241.3 & 195.6 & 191.0 & 63.0 & 520.0 & 30.1 & 8.8 & 29.2 & 20.3 & 41.6 & 2.9 & 2.1 & 2.8 & $<\mathrm{DL}$ & 5.6 & 5.8 & 1.7 & 5.3 & 4.3 & 8.3 \\
\hline LA & 4 & 760.4 & 244.9 & 721.0 & 514.3 & 1085.3 & 18.2 & 5.1 & 19.6 & 10.9 & 22.7 & 15.9 & 18.6 & 10.4 & 1.4 & 41.4 & 8.8 & 10.8 & 4.9 & 1.1 & 24.2 \\
\hline $\mathrm{RE}$ & 1 & 523.0 & - & 523.0 & 523.0 & 523.0 & 46.8 & - & 46.8 & 46.8 & 46.8 & 11.4 & - & 11.4 & 11.4 & 11.4 & 5.5 & - & 5.5 & 5.5 & 5.5 \\
\hline All & 79 & 495.6 & 493.5 & 338.0 & 53.0 & 2927.8 & 25.1 & 24.8 & 20.3 & $<\mathrm{DL}$ & 186.0 & 7.0 & 8.8 & 3.4 & $<\mathrm{DL}$ & 46.4 & 7.8 & 7.3 & 6.2 & $<\mathrm{DL}$ & 40.0 \\
\hline
\end{tabular}
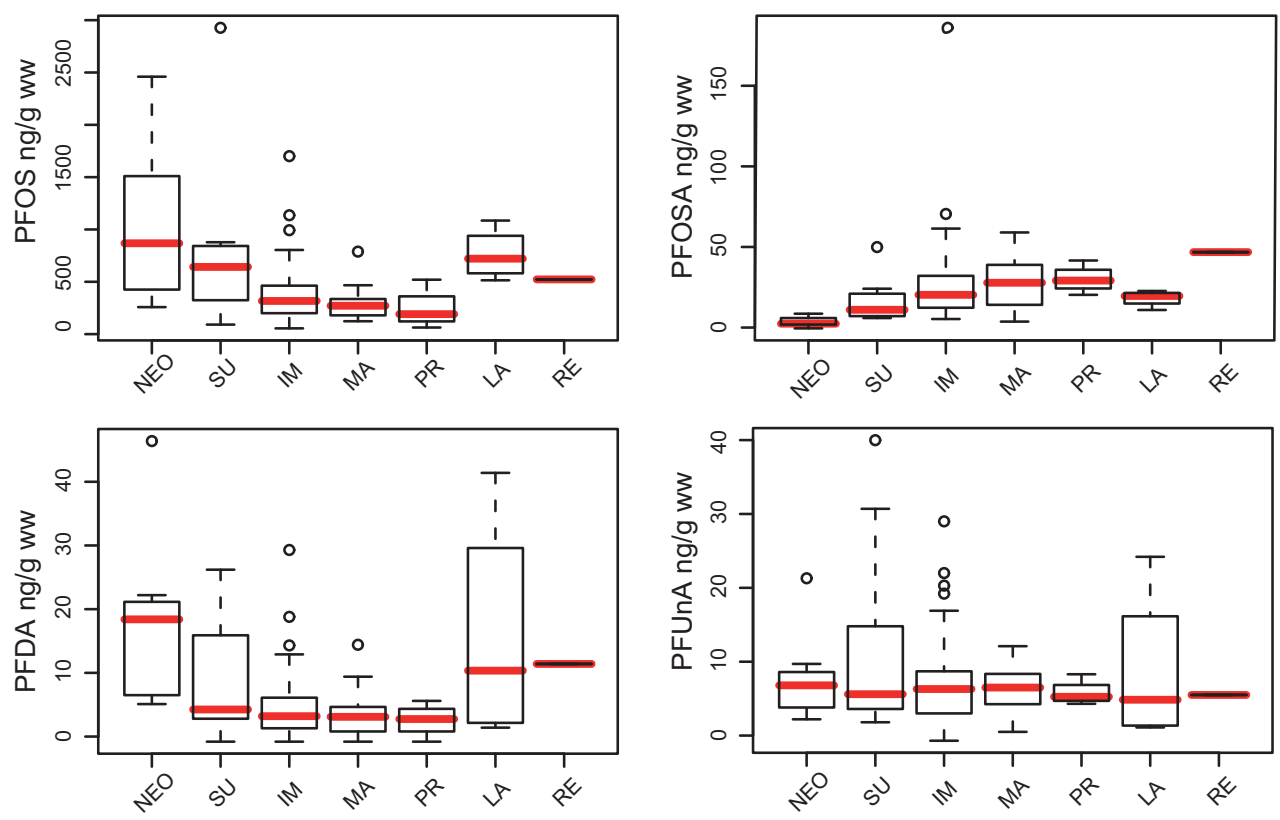

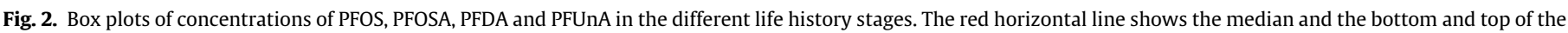

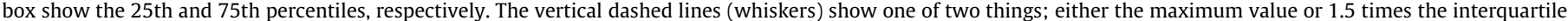

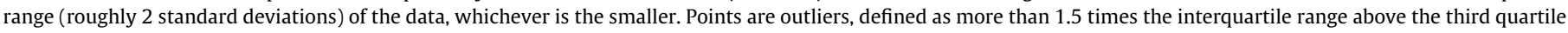

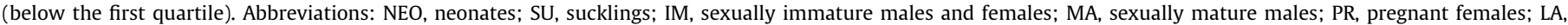

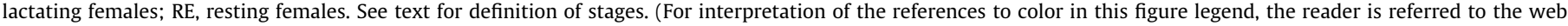
version of this article.)

the fetal stage. Previously, Van de Vijver et al. (2003) have reported higher PFC loads in juvenile harbor porpoises than in adults, and a porpoise fetus has been show to have almost three times higher liver tissue concentration of PFOS in than the mother. Similar rates have been reported in other odontocetes, e.g., bottlenose dolphin, marine tucuxi (Sotalia guianensis) (Dorneles et al., 2008) and melon-headed whale (Peponocephala electra) (Hart et al., 2008). Beside neonates, two other life history categories showed higher PFOS burdens, namely sucklings of both sexes which had significantly higher loads than non-suckling juveniles (Kruskal-Wallis test, $p=0.03$ ) and lactating females which had significantly higher levels than non-lactating mature animals (Kruskal-Wallis test, $p=0.005$ ) (Fig. 2). The differences between neonates on one side and immature specimens, mature males or pregnant females on the other side were statistically significant (Kruskal-Wallis test, $p=0.01,0.01,0.02$, respectively). The increased concentrations in sucklings are probably caused by maternal transfer through lactation and/or residual PFOS from placental transfer. Van de Vijver et al. (2003) found significantly higher PFOS levels in female porpoises than in males. They speculated that PFCs are not being 
excreted through lactation. More recently, however, PFCs have been detected in bottlenose dolphin milk in substantial concentrations, indicating a significant transfer to the offspring (Houde et al., 2006). Alternative explanations for higher loads in females may be that they feed closer to shore, and hence closer to the sources than males as indicated by stable isotope analysis on Black Sea harbor porpoise (Das et al., 2004) or that they feed on a somewhat higher trophic level, and hence receive more biomagnified loads, which is not unlikely given their larger size. However, non-lactating females from our sample have PFOS burdens similar to male and immature porpoises, so previous reports of higher concentrations in females may be an artifact caused by the inclusion of lactating animals. In our sample, lactating females had significantly (Kruskal-Wallis test, $p<0.01$ ) higher PFOS loads than other mature porpoises. One possible explanation for this could be that female porpoises increase their food consumption substantially during lactation and thus increase their dietary exposure. A captive harbor porpoise at the Fjord \& Belt centre in Denmark approximately doubled its food intake during lactation (M. Wahlberg, pers. comm.). Another possibility is that lactating females reduce their urine production and/or protein metabolism during lactation. Houde et al. (2006) estimated that urinary excretion of PFOS almost balanced dietary intake in bottlenose dolphins (Tursiops truncatus). With few exceptions, cetaceans do not drink seawater, but rely on water obtained from diet and metabolism (Ortiz, 2001). Relative to other odontocetes, harbor porpoises have a brief and intense lactation period (Oftedal, 1997). The limited water supply and the demands of water and protein for milk production may lead to reduced urine volume and/or different urine composition and protein metabolism in lactating porpoises. There are indications that gray seals (Halichoerus grypus) reduce their protein catabolism and urea excretion during their much briefer lactation (Schweigert, 1993), while metabolic adaptations in the harbor porpoise remain speculative.

\subsubsection{PFC profiles}

Aside from the elevated concentrations of PFOS in neonates, sucklings and lactating females, there were some other interesting differences among the life history stages. Neonates, sucklings and lactating females showed lower concentrations of PFOSA, while neonates and lactating females had a different PFDA:PFUnA ratio relative to the other stages. Fig. 3 shows a bar plot of the PFC-profiles of the life history stages.

The generally similar PFC profiles of neonates and lactating females give further support to reduced urine excretion and/or protein catabolism as the background for their elevated PFOS levels. In bottlenose dolphins, PFCs with shorter chain length are more easily excreted with urine than those with longer chain length (Houde et al., 2006). The two PFCAs that were found above detection limit in most samples (PFDA and PFUnA) show significantly different ratios in neonates and lactating females relative to all other life history stages except 'resting females' with only one individual (Kruskal-Wallis tests, all $p<0.05$ ). In both neonates and lactating females, there was a higher concentration of the $C_{11}$ congener, $P F u-$ $\mathrm{NA}$, while in the other life history stages the $\mathrm{C}_{10}$ congener, PFDA was more prevalent. In absolute concentrations, PFDA showed the same trend relative to life history categories as PFOS with neonates having significantly higher concentrations than immature specimens, mature males or pregnant females (Kruskal-Wallis test, $p<0.01,<0.01,0.02$, respectively), while PFUnA levels did not differ among the life history stages (Kruskal-Wallis test, $p=0.99$ ). This indicates that the differences in ratio between the two compounds are caused by differences in the excretion rate of PFDA among the stages.

Surprisingly, PFOSA levels showed a reversal of the pattern found in the PFOS levels with neonates, sucklings and lactating animals having lower levels than the other categories, the differences between neonates and all other categories except resting with only one individual being statistically significant (Kruskal-Wallis test, $p<0.02$ in all cases). This reversed pattern is not explained by a general negative correlation of PFOS and PFOSA; when neonates, sucklings and lactating females were removed, there were significant positive correlations between PFOSA and the other three regularly detected PFCs (Spearman correlation, $p<0.03$ in all cases). Biotransformation of PFOSA to PFOS has been demonstrated in vertebrate liver microsomes (Tomy et al., 2004; Xu et al., 2004). This may mean that biotransformation of PFOSA to PFOS is positively correlated with endoplasmic reticulum activity, i.e., protein synthesis. Increased levels of protein synthesis occur during growth and lactation (Waterlow, 1995), fitting well with the lower PFOSA levels in neonates, sucklings and lactating females reported here.

Given the high calving rate and intensive life cycle of the harbor porpoise (Read and Hohn, 1995), adult females frequently switch among the different life history stages used in this study. The similar PFC profiles found in adult males and non-lactating adult females and higher levels in lactating females indicate rapid changes in response to reproductive status and thus dynamic turnover of these compounds in harbor porpoises.

The PFC burdens did not show a significant relationship with age after removal of neonates, sucklings and lactating females (Spearman correlation, $p>0.11$ in all cases). Lack of age trends have also been reported in other studies of marine mammals, e.g., harbor porpoise (Van de Vijver et al., 2007), ringed seal (Butt et al., 2008; Kannan et al., 2002), harbor seal (Van de Vijver et al., 2005), gray seal (Kannan et al., 2002) and melon-headed whale (Hart et al., 2008). Decrease with age has been reported in

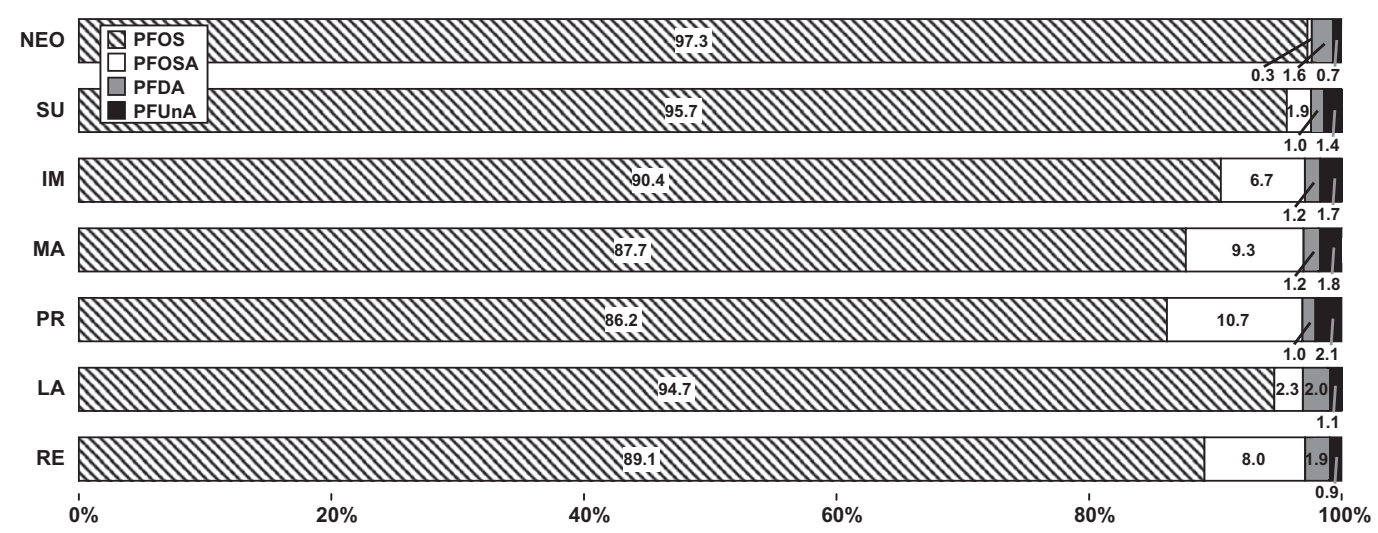

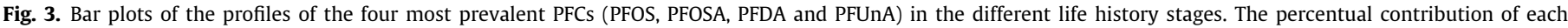
compound is given on or below the bars. 
bottlenose dolphins (Houde et al., 2005, 2006) and increase with age in marine tucuxi (Dorneles et al., 2008) and polar bears (Smithwick et al., 2005; Sonne et al., 2008). Although not all these studies have taken life history events into account, it seems that the kinetics of PFCs differ according to species and, possibly, trophic level.

\subsection{Temporal trends}

Basic statistics on PFC concentrations in the different sampling years are given in Table 3. Although our sample sizes are large relative to comparable studies, the temporal trends in the data were, with one exception, not significant. Differences among life history categories meant that the trends must be calculated on a subset of the original sample. After removal of neonates, sucklings and lactating females we found that levels of PFOS and PFOSA were stable or showed moderate increase during the 25 year period from 1980 to 2005, while the two PFCAs consistently detected (PFDA and PFUnA), showed stronger increases, the latter with high significance $(p<0.01)$. The trend of an annual increase of $8.8 \%$ of PFUnA could be described as a log-linear increase (exponential increase on ordinary scale) shown by non-significant non-linear component (Table 4 and Fig. 4). Other studies of PFOS time trends in northern Europe (herring gull eggs from northern Norway (Verreault et al., 2007), guillemot eggs from the Swedish Baltic (Holmstrom et al., 2005) and eel from Holland (Kwadijk et al., 2010) have reported an increase in PFOS from the 1970 s or 80 s to the mid-1990s followed by decline. Our data may conceal the same trend; although the median values do not show a trend, with year 1992-2000 containing some values above $1000 \mathrm{ng} \mathrm{g}^{-1} \mathrm{ww}$, which are not found before or after. Other studies e.g., polar bears in the remote Arctic regions have showed increasing concentrations for most PFCs, as e.g. in East Greenland between 1982 and 2006 (Dietz et al., 2008). Studies on Canadian and Alaskan polar bears have likewise indicated an increase in PFCs in the period from 1982 to 2002 (Smithwick et al., 2006). Studies of ringed seals from Greenland waters have also shown increases in PFCs in both East and West Greenland between 1982 and 2003 (Bossi et al., 2005), whereas time trend studies on PFCs in Canadian ringed seals from two regions have shown both increases and in some cases followed by decreases, depending on the area, period, and compound in question (Butt et al., 2007). PFCs in Arctic biota mostly originate from long range transport while in the North Sea, local sources predominate (Ahrens et al., 2010).

There is a scarcity of temporal trend studies of PFCAs from northwestern Europe with which to compare the increasing time trends we detected. Ahrens et al. (2009) reported constant levels of PFCAs in their study of harbor seal liver tissue in the German North Sea from 1999 to 2008. In studies in the Arctic, PFCAs have also been reported to show temporal increases in years concurrent with the current study, e.g., in ringed seal liver from East and West

Table 4

Statistics of the regression analyses of time trends. Neonates, sucklings and lactating females are excluded from the analyses. DL, detection limit.

\begin{tabular}{|c|c|c|c|c|c|}
\hline & \multicolumn{2}{|c|}{ Linear component } & \multicolumn{2}{|c|}{ Non-linear component } & \multirow[t]{2}{*}{ Annual change (\%) } \\
\hline & $F$-values & $p$-Values & $F$-values & $p$-Values & \\
\hline PFOS & 0.03 & 0.87 & 0.47 & 0.65 & +0.5 \\
\hline PFOSA & 1.07 & 0.35 & 1.58 & 0.30 & +2.9 \\
\hline PFDA $^{\mathrm{a}}$ & 2.49 & 0.18 & 0.19 & 0.84 & +8.4 \\
\hline PFUnA & 24.4 & $<0.01$ & 0.87 & 0.48 & +8.8 \\
\hline PFHxS & \multicolumn{5}{|c|}{5 years with annual median below DL } \\
\hline PFOA & \multicolumn{5}{|c|}{8 years with annual median below DL } \\
\hline PFNA & \multicolumn{5}{|c|}{7 years with annual median below DL } \\
\hline
\end{tabular}

a 1 year with median below DL.
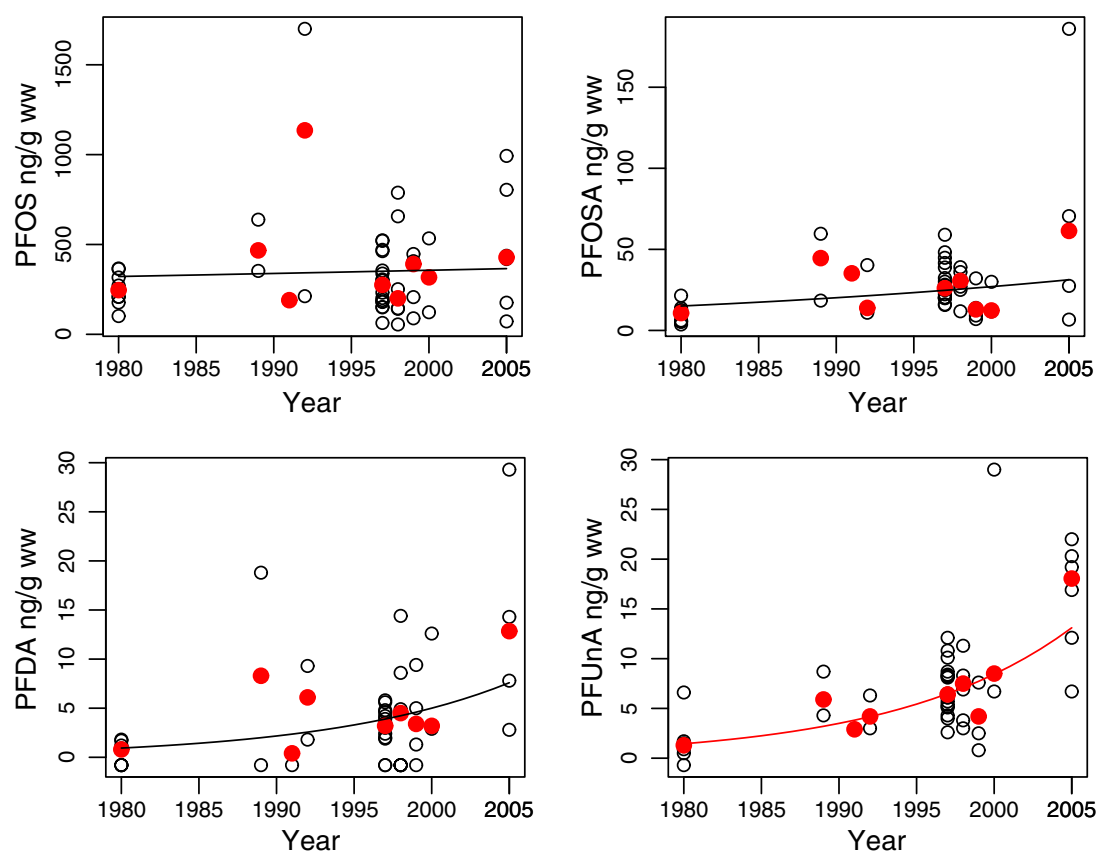

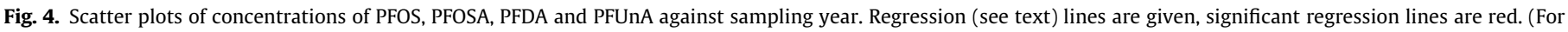
interpretation of the references to color in this figure legend, the reader is referred to the web version of this article.) 
Greenland (Bossi et al., 2005) and polar bear liver en East Greenland (Dietz et al., 2008). General profiles of perfluorocarboxylates (PFCAs) in biota are characterized by high proportions of odd and long carbon-chain length compounds $(C>9)$. PFOA and PFNA are almost exclusively produced industrially (95\% of the industry-wide PFCA emissions estimated in 2000, Prevedouros et al., 2006). However, PFOA and PFNA products contained longer carbon-chained impurities (PFCAs up to $C_{15}$ ), which are more bioaccumulative than the $\mathrm{C}_{8}$ and $\mathrm{C}_{9}$ PFCAs, which may partially explain the presence of PFCAs with $C>9$ in marine mammals. Long-chain PFCAs may also be formed from oxidation (both atmospheric and biological) of fluorotelomer-based precursors, such as fluorotelomer alcohols and olefins. In our samples, the concentrations of PFDA and PFUnA, the $C_{10}$ and $C_{11}$ PFCAs, were closely correlated especially among the neonates and lactating females (Spearman correlation $\rho=0.95, p<0.001$ vs $\rho=0.58, p<0.001$ for the other life history categories), which we propose to eliminate PFCs at much lower rates than other life history categories. This strongly indicates a common source of these two compounds.

\subsection{Health implications}

Most of the analyzed concentrations in harbor porpoises were low compared to higher trophic species such as the polar bears and the effect concentrations. However, many of the highest concentrations were found in neonates and suckling porpoises which is of concern as toxic effects on the development of the central nervous system and reproductive organs as well as lower postnatal survival rates in relation to PFC exposure have been demonstrated in laboratory animals. (Liu et al., 2010; Lau et al., 2003; Luebker et al., 2005). The levels of observable adverse effects in laboratory rats and cynomolgous monkey (Macaca fascicularis) (Seacat et al., 2002; Lau et al., 2003) are more than an order of magnitude higher than the concentrations we found in neonate porpoises.

\section{Conclusions}

We found substantial differences in PFC concentrations among life history stages, probably as a consequence of maternal transfer of PFCs and metabolic differences related to the fetal stage, growth and lactation. Some compounds showed reversed concentration patterns relative to life history. Such differences should be taken into account when PFC levels in wildlife are evaluated. Despite the international efforts to reduce PFOS use and emissions since 2001, we did not detect a decreasing trend of concentrations in North Sea harbor porpoises within the period from 1980 to 2005. PFCA concentrations were found to be increasing. Many of the highest concentrations were found in neonates and suckling harbor porpoises, which is of concern as the developing fetus is more susceptible to toxic effects on the development of e.g., the central nervous system and reproductive organs.

\section{Acknowledgements}

The Natural History Museum, University of Copenhagen, DTUAqua, Danish Forest and Nature Agency, National Environmental Research Institute, University of Aarhus and The Fisheries and Maritime Museum, Esbjerg funded the harbor porpoise sampling and storage. Beside some of the authors, a number of people helped with handling and dissections over the years, including Søren Andersen, Bjarne Clausen, Svend Tougaard, Thyge Jensen, Ursula Siebert and Sigga Joensen. National Environmental Research Institute, Aarhus University provided funding for the chemical analyses. Centre of Wildlife Health provided funding for the data analysis and time used for writing up the manuscript. Inga Jensen skillfully conducted the PFC analyses.

\section{References}

Ahrens, L., Siebert, U., Ebinghaus, R., 2009. Temporal trends of polyfluoroalkyl compounds in harbor seals (Phoca vitulina) from the German Bight, 1999-2008. Chemosphere 76, 151-158.

Ahrens, L., Gerwinski, W., Theobald, N., Ebinghaus, R., 2010. Sources of polyfluoroalkyl compounds in the North Sea, Baltic Sea and Norwegian Sea: evidence from their spatial distribution in surface water. Marine Pollution Bulletin 60, 255-260.

Berthiaume, J., Wallace, K.B., 2002. Perfluorooctanoate, perflourooctanesulfonate, and $\mathrm{N}$-ethyl perfluorooctanesulfonamido ethanol; peroxisome proliferation and mitochondrial biogenesis. Toxicology Letters 129, 23-32.

Bossi, R., Riget, F.F., Dietz, R., 2005. Temporal and spatial trends of perfluorinated compounds in ringed seal (Phoca hispida) from Greenland. Environmental Science \& Technology 39, 7416-7422.

Butt, C.M., Muir, D.C.G., Stirling, I., Kwan, M., Mabury, S.A., 2007. Rapid response of arctic ringed seals to changes in perfluoroalkyl production. Environmental Science \& Technology 41, 42-49.

Butt, C.M., Mabury, S.A., Kwan, M., Wang, X.W., Muir, D.C.G., 2008. Spatial trends of perfluoroalkyl compounds in ringed seals (Phoca hispida) from the Canadian Arctic. Environmental Toxicology and Chemistry 27, 542-553.

Das, K., Holsbeek, L., Browning, J., Siebert, U., Birkun, A., Bouquegneau, J.M., 2004 Trace metal and stable isotope measurements (delta C-13 and delta $\mathrm{N}-15$ ) in the harbour porpoise Phocoena phocoena relicta from the Black Sea. Environmental Pollution 131, 197-204.

Dietz, R., Bossi, R., Riget, F.F., Sonne, C., Born, E.W., 2008. Increasing perfluoroalkyl contaminants in east Greenland polar bears (Ursus maritimus): a new toxic threat to the Arctic bears. Environmental Science \& Technology 42, 2701-2707.

Dorneles, P.R., Lailson-Brito, J., Azevedo, A.F., Meyer, J., Vidal, L.G., Fragoso, A.B. Torres, J.P., Malm, O., Blust, R., Das, K., 2008. High accumulation of perfluorooctane sulfonate (PFOS) in marine tucuxi dolphins (Sotalia guianensis) from the Brazilian coast. Environmental Science \& Technology 42 , 5368-5373.

Fryer, R.J., Nicholson, M.D., 1999. Using smoothers for comprehensive assessments of contaminant time series in marine biota. ICES Journal of Marine Science 56, 779-790.

Fryer, R.J., Nicholson, M.D., 2002. Using smoothers for comprehensive assessments of contaminant time-series in the marine environment. ICES Journal of Marine Science 59, 1-14

Giesy, J.P., Kannan, K., 2001. Global distribution of perfluorooctane sulfonate in wildlife. Environmental Science \& Technology 35, 1339-1342.

Hart, K., Kannan, K., Isobe, T., Takahashi, S., Yamada, T.K., Miyazaki, N., Tanabe, S. 2008. Time trends and transplacental transfer of perfluorinated compounds in melon-headed whales stranded along the Japanese coast in 1982, 2001/2002, and 2006. Environmental Science \& Technology 42, 7132-7137.

Hohn, A.A., Lockyer, C., 1995. Protocol for obtaining age estimates from harbor porpoise teeth. Reports of the International Whaling Commission Special Issue $16,494-496$.

Holmstrom, K.E., Jarnberg, U., Bignert, A., 2005. Temporal trends of PFOS and PFOA in guillemot eggs from the Baltic Sea, 1968-2003. Environmental Science \& Technology 39, 80-84.

Houde, M., Wells, R.S., Fair, P.A., Bossart, G.D., Hohn, A.A., Rowles, T.K., Sweeney, J.C. Solomon, K.R., Muir, D.C.G., 2005. Polyfluoroalkyl compounds in free-ranging bottlenose dolphins (Tursiops truncatus) from the Gulf of Mexico and the Atlantic Ocean. Environmental Science \& Technology 39, 6591-6598.

Houde, M., Balmer, B.C., Brandsma, S., Wells, R.S., Rowles, T.K., Solomon, K.R., Muir D.C.G., 2006. Perfluoroalkyl compounds in relation to life-history and reproductive parameters in bottlenose dolphins (Tursiops truncatus) from Sarasota Bay, Florida, USA. Environmental Toxicology and Chemistry 25, 2405-2412.

Johansson, N., Fredriksson, A., Eriksson, P., 2008. Neonatal exposure to perfluorooctane sulfonate (PFOS) and perfluorooctanoic acid (PFOA) causes neurobehavioural defects in adult mice. Neurotoxicology 29, 160-169.

Jones, P.D., Hu, W.Y., De Coen, W., Newsted, J.L., Giesy, J.P., 2003. Binding of perfluorinated fatty acids to serum proteins. Environmental Toxicology and Chemistry 22, 2639-2649.

Kannan, K., Koistinen, J., Beckmen, K., Evans, T., Gorzelany, J.F., Hansen, K.J., Jones, P.D., Helle, E., Nyman, M., Giesy, J.P., 2001. Accumulation of perfluorooctane sulfonate in marine mammals. Environmental Science \& Technology 35, 15931598.

Kannan, K., Corsolini, S., Falandysz, J., Oehme, G., Focardi, S., Giesy, J.P., 2002 Perfluorooctanesulfonate and related fluorinated hydrocarbons in marine mammals, fishes, and birds from coasts of the Baltic and the Mediterranean Seas. Environmental Science \& Technology 36, 3210-3216.

Kannan, K., Tao, L., Sinclair, E., Pastva, S.D., Jude, D.J., Giesy, J.P., 2005. Perfluorinated compounds in aquatic organisms at various trophic levels in a Great Lakes food chain. Archives of Environmental Contamination and Toxicology 48, 559-566.

Kissa, E., 2001. Fluorinated Surfactants and Repellents. Marcel Decker, New York.

Kwadijk, C.J.A.F., Korytar, P., Koelmans, A.A., 2010. Distribution of perfluorinated compounds in aquatic systems in the Netherlands. Environmental Science \& Technology 44, 3746-3751. 
Lau, C., Thibodeaux, J.R., Hanson, R.G., Rogers, J.M., Grey, B.E., Stanton, M.E. Butenhoff, J.L., Stevenson, L.A., 2003. Exposure to perfluorooctane sulfonate during pregnancy in rat and mouse. II: postnatal evaluation. Toxicological Sciences 74, 382-392.

Law, R.J., Bersuder, P., Mead, L.K., Jepson, P.D., 2008. PFOS and PFOA in the livers of harbour porpoises (Phocoena phocoena) stranded or bycaught around the UK. Marine Pollution Bulletin 56, 792-797.

Liu, X.H., Liu, W., Jin, Y.H., Yu, W.G., Wang, F.Q., Liu, L., 2010. Effect of gestational and lactational exposure to perfluorooctanesulfonate on calcium-dependent signaling molecules gene expression in rats' hippocampus. Archives of Toxicology 84, 71-79.

Lockyer, C., 2003. Harbour porpoises (Phocoena phocoena) in the North Atlantic: biological parameters. NAMMCO Scientific Publications 5, 71-89.

Luebker, D.J., York, R.G., Hansen, K.J., Moore, J.A., Butenhoff, J.L., 2005. Neonatal mortality from in utero exposure to perfluorooctanesulfonate (PFOS) in Sprague-Dawley rats: dose-response, and biochemical and pharmacokinetic parameters. Toxicology 215, 149-169.

Malinverno, G., Colombo, I., Visca, M., 2005. Toxicological profile of hydrofluoropolyethers. Regulatory Toxicology and Pharmacology 41, 228-239.

Martin, J.W., Smithwick, M.M., Braune, B.M., Hoekstra, P.F., Muir, D.C.G., Mabury, S.A., 2004. Identification of long-chain perfluorinated acids in biota from the Canadian Arctic. Environmental Science \& Technology 38, 373-380.

Midasch, O., Drexler, H., Hart, N., Beckmann, M.W., Angerer, J., 2007. Transplacental exposure of neonates to perfluorooctanesulfonate and perfluorooctanoate: a pilot study. International Archives of Occupational and Environmental Health 80, 643-648.

Miller, M.L., Clark, L.C.J., Wesseler, E.P., Stanley, L., Emory, C., Kaplan, S., 1975. Light microscopic morphometry and fine structure of the liver: a response to perfluorinated liquid emulsions used as artificial blood. Alabama Journal of Medical Sciences 12, 84-113.

Nicholson, M.D., Fryer, R.J., Larsen, J.R., 1998. A robust method for analysing contaminant trend monitoring data. Techniques in Marine Environmental Sciences No. 20 International Council for Exploitation of the Sea, Copenhagen V.

Oftedal, O.T., 1997. Lactation in whales and dolphins: evidence of divergence between baleen- and toothed species. Journal of Mammary Gland Biology and Neoplasia 2, 205-230.

Ortiz, R.M., 2001. Osmoregulation in marine mammals. Journal of Experimental Biology 204, 1831-1844.

Prevedouros, K., Cousins, I.T., Buck, R.C., Korzeniowski, S.H., 2006. Sources, fate and transport of perfluorocarboxylates. Environmental Science \& Technology 40, $32-44$.

R Development Core Team, 2008. An introduction to R: notes on R, a programming environment for data analysis and graphics.

Read, A.J., Hohn, A.A., 1995. Life in the fast lane - the life history of harbor porpoises from the Gulf of Maine. Marine Mammal Science 11, 423-440.

Rüdel, H., Müller, J., Jürling, H., Schröter-Kermani, C., 2010. Retrospective monitoring of perfluorinated compounds in archived herring gull eggs. In: Isobe, T., Nomiyama, K., Subramanian, A., Tanabe, S. (Eds.), Interdisciplinary Studies on Environmental Chemistry - Environmental Specimen Bank TERRAPUB, Tokyo, pp. 81-86.

Schweigert, F.J., 1993. Effects of fasting and lactation on blood chemistry and urine composition in the gray seal (Halichoerus grypus). Comparative Biochemistry and Physiology A - Physiology 105, 353-357.

Seacat, A.M., Thomford, P.., Hansen, K.J., Olsen, G.W., Case, M.T., Butenhoff, J.L. 2002. Subchronic toxicity studies on perfluorooctanesulfonate potassium salt in cynomolgus monkeys. Toxicological Sciences 68, 249-264.
Shaw, S., Berger, M.L., Brenner, D., Tao, L., Wu, Q., Kannan, K., 2009. Specific accumulation of perfluorochemicals in harbor seals (Phoca vitulina concolor) from the northwest Atlantic. Chemosphere 74, 1037-1043.

Smithwick, M., Muir, D.C.G., Mabury, S.A., Solomon, K.R., Martin, J.W., Sonne, C., Born, E.W., Letcher, R.J., Dietz, R., 2005. Perflouroalkyl contaminants in liver tissue from East Greenland polar bears (Ursus maritimus). Environmental Toxicology and Chemistry 24, 981-986.

Smithwick, M., Norstrom, R.J., Mabury, S.A., Solomon, K., Evans, T.J., Stirling, I., Taylor, M.K., Muir, D.C.G., 2006. Temporal trends of perfluoroalkyl contaminants in polar bears (Ursus maritimus) from two locations in the North American Arctic, 1972-2002. Environmental Science \& Technology 40, 1139-1143.

Sonne, C., Bossi, R., Dietz, R., Leifsson, P.S., Rigét, F.F., Born, E.W., 2008. Potential correlation between perfluorinated acids and liver morphology in East Greenland polar bears (Ursus maritimus). Toxicological \& Environmental Chemistry 90, 275-283.

Sørensen, T.B., Kinze, C.C., 1994. Reproduction and reproductive seasonality in Danish harbour porpoises, Phocoena phocoena. Ophelia 39, 159-176.

Tomy, G.T., Budakowski, W., Halldorson, T., Helm, P.A., Stern, G.A., Friesen, K., Pepper, K., Tittlemier, S.A., Fisk, A.T., 2004. Fluorinated organic compounds in an eastern Arctic marine food web. Environmental Science \& Technology 38, 64756481.

Upham, B.L., Park, J.S., Babica, P., Sovadinova, I., Rummel, A.M., Trosko, J.E., Hirose, A., Hasegawa, R., Kanno, J., Sai, K., 2009. Structure-activity-dependent regulation of cell communication by perfluorinated fatty acids using in vivo and in vitro model systems. Environmental Health Perspectives 117, 545551

Van de Vijver, K.I., Hoff, P., Das, K., Van Dongen, W., Esmans, E., Jauniaux, T., Bouquegneau, J.M., Blust, R., De Coen, W., 2003. Perfluorinated chemicals infiltrate ocean waters: link between exposure levels and stable isotope ratios in marine mammals. Environmental Science \& Technology 37, 5545-5550.

Van de Vijver, K.I., Hoff, P.T., Das, K., Van Dongen, W., Esmans, E.L., Siebert, U., Bouquegneau, J.M., Blust, R., De Coen, W.M., 2004. Baseline study of perfluorochemicals in harbour porpoises (Phocoena phocoena) from Northern Europe. Marine Pollution Bulletin 48, 992-997.

Van de Vijver, K.I., Hoff, P., Das, K., Brasseur, S., Van Dongen, W., Esmans, E., Reijnders, P., Blust, R., De Coen, W., 2005. Tissue distribution of perfluorinated chemicals in harbor seals (Phoca vitulina) from the Dutch Wadden Sea. Environmental Science \& Technology 39, 6978-6984.

Van de Vijver, K.I., Hoslbeek, L., Das, K., Blust, R., Joiris, C., De Coen, W. 2007. Occurrence of perfluorooctane sulfonate and other perfluorinated alkylated substances in harbor porpoises from the Black Sea. Environmental Science \& Technology 41, 315-320.

Verreault, J., Berger, U., Gabrielsen, G.W., 2007. Trends of perfluorinated alkyl substances in herring gull eggs from two coastal colonies in northern Norway: 1983-2003. Environmental Science \& Technology 41, 6671-6677.

Wang, T., Wang, Y.W., Liao, C.Y., Cai, Y.Q., Jiang, G.B., 2009. Perspectives on the inclusion of perfluorooctane sulfonate into the Stockholm Convention on persistent organic pollutants. Environmental Science \& Technology 43, 51715175.

Waterlow, C., 1995. Whole-body protein turnover in humans - past, present and future. Annual Review of Nutrition 15, 57-92.

Xu, L., Krenitsky, D.M., Seacat, A.M., Butenhoff, J.L., Anders, M.W., 2004. Biotransformation of N-ethyl-N-(2-hydroxyethyl)perfluorooctanesulfonamide by rat liver microsomes, cytosol, and slices and by expressed rat and human cytochromes P450. Chemical Research in Toxicology 17, 767-775. 